\title{
Longitudinal trends of blood lead levels before and after leaded gasoline regulation in Korea
}

\author{
Se-Eun $\mathrm{Oh}^{1,2}$, Gi Bog Kim${ }^{1}$, Sung Ho Hwang ${ }^{2}$, Mina Ha ${ }^{3}$, Kyoung-Mu Lee ${ }^{1}$ \\ ${ }^{1}$ Department of Environmental Health, Korea National Open University, Seoul, Korea; ${ }^{2}$ National Cancer Center, Goyang, \\ Korea; ${ }^{3}$ Department of Preventive Medicine, Dankook University College of Medicine, Cheonan, Korea
}

\begin{abstract}
The objective of this study was to verify a change in the longitudinal trend of blood lead levels for the Korean population, before and after the regulation of leaded gasolinewhich occurred between 1987 and 1993 in Korea. A total of 77 reports on blood lead levels among general Korean population between 1981 and 2014 were selected, and the results were summarized to have the variables of year, number of subjects, the subjects' range in age, gender, and blood lead concentrations (arithmetic mean). The annual average atmospheric lead levels for four major cities (i.e., Seoul, Busan, Daegu and Cwangju) were collected from the Air Pollution Monitoring Database from 1991, and pilot studies from 1985 to 1990 before the national air quality monitoring system was launched in 1991. Blood lead levels were visualized in a bubble plot in which the size of each bubble represented the sample size of each study, and the annual average concentrations in ambient air were depicted on line graphs. Blood lead levels in the Korean population tended to gradually in-

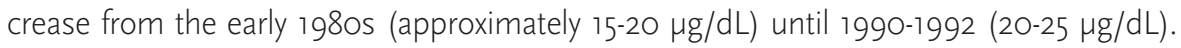
Blood lead levels then began to rapidly decrease until $2014(<2 \mu \mathrm{g} / \mathrm{dL})$. Similar patterns were observed for both adults ( $\geq 20$ years) and younger children/adolescents. The same longitudinal trend was observed in annual average atmospheric lead concentration, which suggests a significant correlation between air lead concentration and blood lead concentration in the general population. In conclusion, the regulation of leaded gasoline has significantly contributed to the rapid change in blood lead concentrations. And, the regulation of other sources of lead exposure should be considered to further decrease blood lead levels in the Korean population.
\end{abstract}

Keywords: Lead exposure, Blood lead level, Leaded gasoline, Ambient air

\author{
Correspondence: Kyoung-Mu Lee \\ Department of Environmental Health, \\ Korea National Open University, 86 \\ Daehak-ro, Jongno-gu, Seoul 03087, Korea \\ E-mail:kmleeg2@knou.ac.kr
}

Received: December 21, 2016

Accepted: October 30, 2017

Published: October 30, 2017

This article is available from: http://e-eht.org/

\section{INTRODUCTION}

Lead is a soft, silver-heavy metal that is one of the most toxic heavy metals, and has been widely used since at least $3000 \mathrm{BC}$. Most leads are emitted from automobile exhaust and many manufacturing processes such as lead smelting, battery manufacturing, pigment manufacturing, ship repairs, and printing [1]. People are exposed to lead through everyday necessities and products such as air, water, smears, fertilizers, crops, ceramics, and toys [2]. All automobiles produced in South Korea (hereafter Korea) until June 1987 used tetraethyl lead to prevent engine knocking. Moreover, the number of automobiles in the mid to late 1980s tripled, suggesting a potential spike in leaded gasoline usage [3]. The Ministry of Environment decided to introduce unleaded fuels to reduce harmful gases emitted by cars and to prevent further air pollution in preparation for the 1988 Olympics [4]. A catalytic converter installation requirement was enforced, and regulation regarding the manufacturing of automobiles was carried out, which led to the appearance of unleaded fuel in the markets. The sale of leaded fuel was prohibited and leaded fuel was fully replaced by unleaded fuel by 1993 [5]. However, there is little information regarding actual usage of either 
leaded or unleaded fuel.

Lead takes longer time to be excreted from the body than other heavy metals, so it accumulates_causing anemia, kidney damage, stomachaches, seizures, encephalopathy, and paralysis. Lead has a shorter half-life in blood (20 days) and soft tissue (40 days), and a longer half-life in bones (10-30 years). Hence, a person's blood lead level reflects both recent and past exposure levels [6]. For adults, even low level exposure reduces kidney function and increases blood pressure, and there have been reports detailing increased chances of miscarriage in women and reduced sperm production in men [7]. Other reports have shown that even low level lead exposure may cause delayed language development and neurobehavioral or cognitive disabilities [8].

The Centers for Disease Control and Prevention (CDC) set reference value of blood lead level as $10 \mu \mathrm{g} / \mathrm{dL}$ for adults and approximately $5 \mu \mathrm{g} / \mathrm{dL}$ for children [9]. Lead exposure levels in children, who are particularly sensitive, are lower in the US and Canada than in Korea [10]. The German Federal Environment Agency Human Biomonitoring Commission originally set reference value of blood lead level as $25 \mu \mathrm{g} / \mathrm{dL}$ but retracted the recommended level in 2009 [11] due to reports that blood lead levels below even $10 \mu \mathrm{g} / \mathrm{dL}$ may cause cognitive disabilities affecting brain development [12].

Main focus of international researches was the health effects of direct occupational exposure in 1970s [13], environmental lead exposure in 1980s [14], and the health effects of low level exposure ever since [12]. Research regarding air pollution and blood lead levels has been widely conducted in the US and Europe, such as that on the relationship between lead exposure from air and soil and child blood lead levels [15,16], and atmospheric lead concentration and blood lead levels following the regulation of leaded fuels $[17,18]$.

In Korea, there have been active researches on general adult populations to evaluate the association between blood lead levels and the lifestyles of adults who are not occupationally exposed to lead [19], and to measure blood lead levels among residents in particular areas [20]. However, the number of researches on changes in atmospheric lead levels and blood lead levels is limited. Hence, this research was conducted to evaluate how the blood lead levels among Korean population and annual atmospheric lead concentration changed before and after the regulation of leaded fuels in Korea.

\section{METHODS}

\section{Literature Search and Selection \\ Blood Lead Levels}

Keywords, such as 1) blood lead, 2) lead intoxication, 3) atmo- spheric lead, and 4) atmospheric heavy metals, were used to find data regarding blood lead levels in Korean population. Research Information Sharing Services, Korea Information Sharing Service, Google Scholar, and other databases were used to collect thesis, academic papers, project reports etc. with a total of 124 references initially collected from 1968 to December 2014. The papers or reports that presented results regarding occupational exposure to a high concentration of lead $(n=23)$, health surveys of residents living near industrial complex areas $(n=21)$, and articles from 1960s and 1970s that did not have clearly stated analytic methods of lead $(n=3)$ were all excluded. In most cases, blood lead levels were measured by the method of atomic absorption spectrophotometer, despite the fact that there were some differences in the composition of the additive (diluent) in the pretreatment process.

After ensuring that all papers utilizing the Korean National Health and Nutrition Examination Survey and the Korean National Environment Survey had no overlap, a total of 77 references, with origins spanning from 1980 to 2014, were chosen for the quantitative analysis (Figure 1). Total 49559 individuals (12 115 men adults, 11097 women adults, 22507 children/adolescents, 3840 others) were included from the 77 aforementioned forms of research.

\section{Atmospheric Lead Concentration}

The data of the annual average atmospheric lead concentration from 1991 to 2013 were collected from the Annual Report of Air Quality in Korea, published by the National Institute of

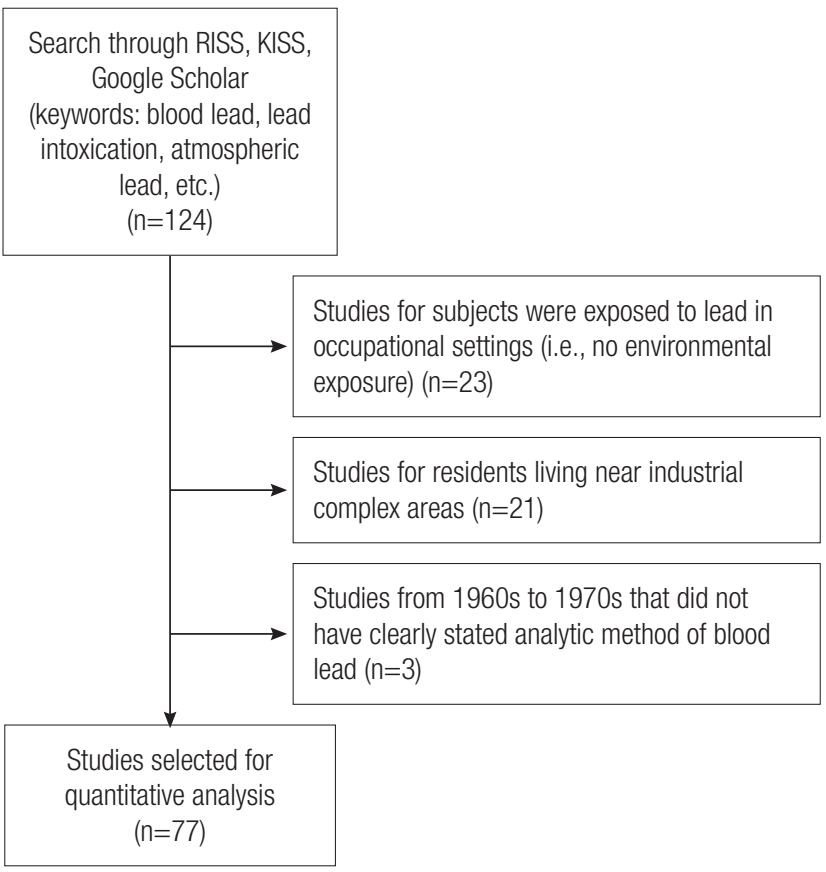

Figure 1. Flow chart for literature search and selection. RISS, Research Information Sharing Services; KISS, Korea Information Sharing Service. 
Environmental Research (NIER). The atmospheric lead concentration was measured 5 times a month in the National Ambient Air Monitoring System (NAMIS) which started in 1991. The results were first verified by the managing institute, then sent to the NAMIS, and finally forwarded to NIER to be saved in database format.

Among preliminary studies, prior to 1991, the studies which monitored and measured atmospheric pollution over a period of at least 10 months annually were used for data prior to 1991 . Any study that did not clearly state the location, method, and number of measurements was excluded. Finally, data from 1985, 1986, 1988, and 1990 were chosen for the analysis. Data from 1987 was excluded due to changes in the measurement method of atmospheric lead that caused the data to lose relevance. Because pre-1991 data were limited to Seoul, Busan, Daegu, and
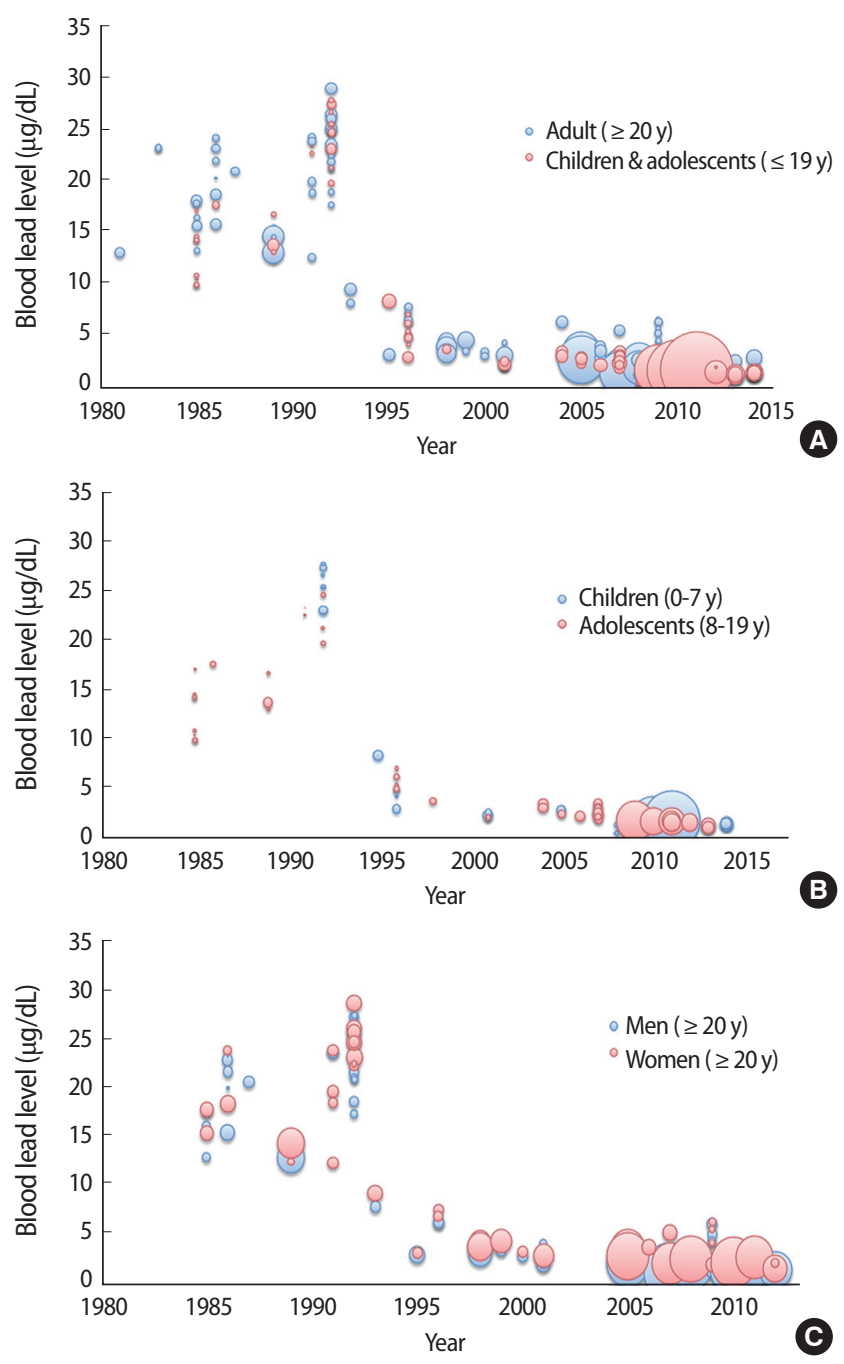

Figure 2. Changes in the trends of blood lead concentrations. (A) Distribution for concentrations of blood lead in adults and children (1984-2014). (B) Distribution for concentrations of blood lead in children and adolescents (1985-2014). (C) Distribution for concentrations of blood lead in adults (1985-2013).
Gwangju, the data from 1991 to 2013 were also limited to results from these four cities, as well.

\section{Data and Analysis \\ Blood Lead Levels}

If possible, the results from selected references were grouped into three different age categories: 0-7 years old children, 8-19 years old adolescents, and adults 20 years old and above. Each research was then summarized and organized to have the following variables, year conducted, research title, researcher, number of subjects, gender, and region (urban vs. rural). Because most research provided arithmetic means of blood lead levels, arithmetic mean was selected as a representative value. The average blood lead levels of the general population in each research were shown in bubble plots of which the size is proportional to the number of subjects. Figure 2 shows the bubble plot by age group and gender.

\section{Atmospheric Lead Concentration}

The trends in the annual average atmospheric lead concentration for Seoul, Busan, Daegu, and Gwangju were shown in line

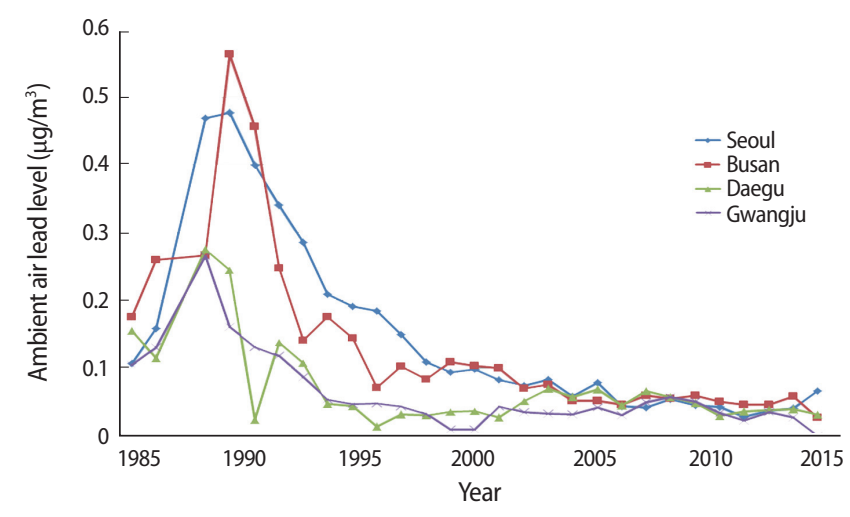

Figure 3. Annual changes in the ambient air concentrations of lead from 1985 to 2013. Source from National Institute of Environmental Research. Annual report of air quality in Korea 2013. Incheon: National Institute of Environmental Research; 2014 [21].

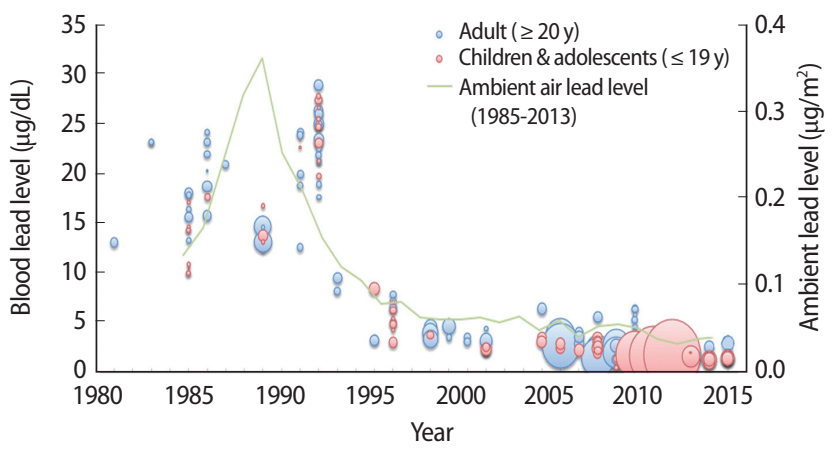

Figure 4. Distribution for concentrations of blood lead and ambient lead in Korea. 
graphs (Figure 3)[21]. In addition, to evaluate the relationship between the atmospheric lead concentration (average of the four cities) and blood lead levels, the bubble plot and the line graph were depicted conjointly (Figure 4).

\section{Statistical Analysis}

The data collected were analyzed using the SAS version 9.4 (SAS Institute Inc., Cary, NC, USA), and the statistical significance was evaluated at $p<0.05$. Blood lead levels were compared for three periods, before lead regulation (1980-1986), during the regulation implementation period (1987-1992), and after the implementation (1993-2014). In a subgroup analysis by region, data were separated by urban and rural regions, and nationwide research or that from unspecified regions were removed from the analysis. In a subgroup analysis by gender, data from men and women genders were separated for adults only considering that most researches regarding children/adolescents did not provide gender-specific data. Also, according to the age of the subjects, those who are 20 years old or above years old were grouped as adults and those who are below 20 years old were grouped as children/adolescents. Summarized blood lead levels were shown as arithmetic mean and standard deviation weighted by number of subjects of each studies [22]. The $t$-test was used to test the difference of blood lead concentrations by region, gender, and age.

In addition, to evaluate how blood lead levels changed over time after peaking in 1992, the correlation coefficient between year and blood lead levels were calculated for each time period
( $\leq 1992$ and $\geq 1993$ ). The correlation coefficient between the annual average atmospheric lead concentration and year was also calculated for each time period.

\section{RESULTS}

\section{Blood Lead Levels}

The distribution of blood lead levels by region, gender and age is shown in Table 1. Overall, the analysis revealed that higher blood lead levels were observed in urban areas $(9.04 \pm 8.47 \mu \mathrm{g}$ / $\mathrm{dL})$ than in rural areas $(5.56 \pm 6.85 \mu \mathrm{g} / \mathrm{dL})$, higher levels in men $(6.10 \pm 6.97 \mu \mathrm{g} / \mathrm{dL})$ than in women $(4.44 \pm 5.72 \mu \mathrm{g} / \mathrm{dL})$, and higher levels in adults $(5.31 \pm 6.46 \mu \mathrm{g} / \mathrm{dL})$ than in adolescents/ children $(2.75 \pm 3.95 \mu \mathrm{g} / \mathrm{dL})$, and all these results were statistically significant. The overall results were not completely consistent when time periods were divided into 1980-1986, 1987 1992, and 1993 -2014 — most likely that studies which involve larger number of participants tended to have bigger influence when there are fewer studies in each divided category.

\section{Changes in the Blood Lead Level Among General Korean Population}

Figure 2A shows the distribution of blood lead levels for both adults and children/adolescents. The blood lead level increased from early 1980s, peaked in $1992(28.76 \mu \mathrm{g} / \mathrm{dL})$, and rapidly decreased to a value below $2 \mu \mathrm{g} / \mathrm{dL}$ since 2000s. While adults tended to have higher values when compared to children/adolescents, the trends in annual changes were similar between

Table 1. Distribution of blood lead levels by region, gender, and age

\begin{tabular}{|c|c|c|c|c|c|c|}
\hline \multirow{2}{*}{ Variable } & & \multirow{2}{*}{$\mathrm{n}$} & \multicolumn{4}{|c|}{ Blood lead level ( $\mu \mathrm{g} / \mathrm{dL})$} \\
\hline & & & 1980-1986 & 1987-1992 & 1993-2014 & Whole period \\
\hline \multirow[t]{3}{*}{ Area } & Urban & 10407 & $17.35 \pm 2.36$ & $20.39 \pm 5.60$ & $3.54 \pm 1.78$ & $9.04 \pm 8.47$ \\
\hline & Rural & 4422 & $17.38 \pm 5.13$ & $18.33 \pm 4.44$ & $2.25 \pm 1.18$ & $5.56 \pm 6.85$ \\
\hline & $p$-value ${ }^{\mathrm{a}}$ & & 0.91 & $<0.001$ & $<0.001$ & $<0.001$ \\
\hline \multirow[t]{3}{*}{ Gender } & Men & 12115 & $18.28 \pm 2.46$ & $20.88 \pm 5.31$ & $3.09 \pm 1.24$ & $6.10 \pm 6.97$ \\
\hline & Women & 11097 & $18.07 \pm 3.35$ & $17.86 \pm 5.34$ & $2.31 \pm 1.03$ & $4.44 \pm 5.72$ \\
\hline & $p$-value ${ }^{\mathrm{a}}$ & & 0.33 & $<0.001$ & $<0.001$ & $<0.001$ \\
\hline \multirow[t]{3}{*}{ Age } & Adult & 23212 & $18.17 \pm 2.94$ & $19.69 \pm 5.52$ & $2.71 \pm 1.21$ & $5.31 \pm 6.46$ \\
\hline & Children/adolescents & 22507 & $13.53 \pm 3.01$ & $21.37 \pm 4.93$ & $1.94 \pm 0.87$ & $2.75 \pm 3.95$ \\
\hline & $p$-value ${ }^{\mathrm{a}}$ & & $<0.001$ & $<0.001$ & $<0.001$ & $<0.001$ \\
\hline
\end{tabular}

Values are presented as weighted arithmetic mean \pm standard deviation.

${ }^{a} p$-values by calculated Student $t$-test.

Table 2. Change in longitudinal trend of blood lead level and ambient lead concentration in Korea

\begin{tabular}{lccccc}
\hline & \multicolumn{2}{c}{$\leq 1992$} & & \multicolumn{2}{c}{$\geq 1993$} \\
\cline { 2 - 3 } \cline { 5 - 6 } & Correlation coefficient & $p$-value & & Correlation coefficient & $p$-value \\
\hline Blood lead level $(\mu \mathrm{g} / \mathrm{dL})$ & 0.65 & $<0.001$ & -0.67 & $<0.001$ \\
Ambient air lead level $\left(\mu \mathrm{g} / \mathrm{m}^{2}\right)$ & $\mathrm{NC}$ & & -0.86 & $<0.001$ \\
\hline
\end{tabular}

NC, not calculated.

${ }^{a} \mathrm{NC}$ due to apparent curvilinear relationship between year and ambient lead level from 1985 to 1992 with a peak observed in 1989. 
these groups. Figure 2B shows the blood lead levels of children/ adolescents based on age (0-7, 8-19). Although overall results are difficult to compare because there were no statistics from studies conducted on 0-7 years old children in 1980s, trends appeared to be similar after 1992. Figure 2C shows the distribution of blood lead levels of adults based on gender. Although men generally had higher lead levels than women, there were no clear differences in the trends in annual changes.

\section{Changes in the Annual Average Atmospheric Lead Concentration}

The changes in annual average atmospheric lead concentration for the four cities (Seoul, Busan, Daegu, and Gwangju) are shown in Figure 3. The annual average atmospheric lead concentration began at $0.1-0.2 \mu \mathrm{g} / \mathrm{m}^{3}$ in 1985 but rapidly increased until 1988 (Daegu, Gwangju) and 1989 (Seoul, Busan). In 1989, both Seoul and Busan had a particularly huge increase of 0.5 and $0.6 \mu \mathrm{g} / \mathrm{m}^{3}$, respectively. However, the concentrations began to decrease rapidly in 1990, with a concentration of under $0.1 \mu \mathrm{g} / \mathrm{m}^{3}$ after 2010 .

\section{Association Between Atmospheric Lead Concentration and Blood Lead Levels}

Figure 4 shows the change in annual average atmospheric lead concentration (average of the four cities) and the change in blood lead levels among general Korean population conjointly. It can be said that both the annual average atmospheric lead concentration and blood lead levels increased until the beginning of the regulation of leaded fuels, and fell dramatically afterwards. Although the location of each maximum does not coincide exactly, similar trends were observed for both.

Prior to 1993, the correlation coefficient between blood lead level and year was $0.65(p<0.001)$, indicating a strong positive relationship, however it was $-0.67(p<0.001)$ after 1993 , indicating a negative relationship which is a dramatic change in the trends (Table 2). The correlation coefficient for atmospheric lead concentration and year was not calculated for the period of 1985-1992 due to its clear curvilinear relationship that peaked in 1989. On the other hand, the correlation coefficient for $\geq 1993$ was $-0.86(p<0.001)$, indicating a strong negative correlation.

\section{DISCUSSION}

This research highlighted and compared the changes in the annual average atmospheric lead concentration and blood lead levels among general Korean population before and after the regulation of leaded fuels (1987-1992) in Korea. The results verified an increasing trend in both the atmospheric lead concentration and blood lead levels prior to the regulation of leaded fuels, which began to decrease as the regulation began.

It is quite clear that the drastic decrease in Korea's annual average atmospheric lead concentration from 1989 is due to the regulation of leaded fuels, or the imperative for non-leaded fuels [5]. In support of this observation, Park [23] found that lead concentration in Korea's major cities appeared to peak in either 1988 or 1989 and started to decrease in 1990. This decrease in lead concentration could be attributed to the successful implementation of a government environmental policy.

In addition, this research directly shows that the decrease in atmospheric lead concentration led to the decrease in blood lead levels. Although people can be exposed to lead through various sources, exposure through inhalation is known to be most prevalent if atmospheric lead concentration is high. Nevertheless, more discussion is needed to explain why the time frame for the decrease in atmospheric lead concentration does not exactly coincide with the time frame of the decrease in blood lead levels. While the annual average atmospheric lead concentration peaked in 1989 and began to decrease, the blood lead levels of Korean people peaked in 1992 and then began to decrease, resulting in a three year difference in comparison. Blood lead concentrations interestingly decreased in 1989, and showed a slight increase in 1991 and 1992. However, because there was no research conducted in 1988 and 1990, and the only research from 1989 was conducted in a rural region, the blood lead level may have even decreased prior to 1992. According to prior research, the blood lead concentrations of adults in urban areas were $6.38 \pm 2.86 \mu \mathrm{g} / \mathrm{dL}$, which were significantly higher than in rural areas, which had a value of $4.50 \pm 2.87 \mu \mathrm{g} / \mathrm{dL}$ [24]. These were also reflected in children, with $1.41 \pm 1.17 \mu \mathrm{g} / \mathrm{dL}$ in rural regions and $1.48 \pm 1.45 \mu \mathrm{g} / \mathrm{dL}$ in urban areas [25]. Moreover, this study revealed that blood lead concentrations in urban areas $(9.04 \pm 8.47 \mu \mathrm{g} / \mathrm{dL})$ were higher than those in rural regions $(5.56 \pm 6.85 \mu \mathrm{g} / \mathrm{dL})$.

The reduction of blood lead levels in general population and atmospheric lead concentration after the regulation of leaded fuels can be observed in international cases as well. For example, in the US, after lead-based paint was prohibited from 1973 to 1995 and leaded fuels were prohibited from cars, airplanes, leisure, and ships in 1996 [26], number of cases with blood lead levels $\geq 10 \mu \mathrm{g} / \mathrm{dL}$ began to decrease from over 10 per 1000 in late 1990s to about 6 per 1000 in 2009 [27]. In Taiwan, unleaded fuels were introduced in 1986, and leaded fuels were prohibited in 2000, resulting in a decrease in both atmospheric lead concentration and blood lead levels between 1985 and 2002 [28].

This research may have been limited in a couple of ways. In 
terms of blood lead levels, there was remarkable regional variation. Older research tended to include small number of subjects and not to provide analytic methods in detail. However, we believe that this study can still sufficiently verify the annual changes in atmospheric lead concentration and blood lead concentration before and after the regulation of leaded fuels in Korea.

The drastic decrease in atmospheric lead concentration after the regulation of leaded fuels indicates that the main source of lead contributing to atmospheric lead levels has changed. In other words, the currently low level atmospheric lead concentration could be attributed to emissions from coal combustion and pollutants from China [29]. Furthermore, it also indicates that the main route of exposure to lead has changed from inhalation to ingestion [30].

Recent researches have shown that even low level lead exposure can affect human health especially of susceptible populations such as children. Absorption of heavy metals is known to be much quicker in the body of children to have significant effects on cognitive function [25]. Likewise the US government has lowered the reference value for young children to around 5 $\mu \mathrm{g} / \mathrm{dL}[31]$, the Korean government should continue to monitor blood lead levels, evaluate exposure route and extent of contribution by exposure sources [23], and attempt to reduce level of exposure to lead.

\section{ACKNOWLEDGEMENTS}

This research was supported by a grant (15162KFDA045) from the Korea Food \& Drug Administration in 2015-2016.

\section{CONFLICT OF INTEREST}

The authors have no conflicts of interest associated with the material presented in this paper.

\section{ORCID}

\author{
Se-Eun Oh https://orcid.org/0000-0002-0888-4969 \\ Mina Ha http://orcid.org/0000-0003-1011-9446 \\ Kyoung-Mu Lee http://orcid.org/0000-0003-4100-1694
}

\section{REFERENCES}

1. Korea Centers for Disease Control and Prevention. Blood levels of heavy metal concentration in Korea. Gwacheon: Ministry of Environment; 2005, p. 4 (Korean).

2. Järup L. Hazards of heavy metal contamination. Br Med Bull 2003; 68:167-182.
3. Seoul Metropolitan Government. The 27th statistical annual report of Seoul [cited 2017 Nov 25]. Available from: http://ebook. seoul.go.kr/Viewer/K91HBOT9E5LV (Korean).

4. Choi YI. Korea's experiences on low emission vehicles and unleaded gasoline. In: Korean Society for Atmospheric Environment. Proceedings of the Korean Society of Atmospheric Environment; 2000 Apr 28-29; Suwon, Korea. Seoul: Korean Society for Atmospheric Environment ; 2000, p. 67-75 (Korean).

5. Institute of Research on Traffic and Environment. Understanding regulations for automobile environment management; 2016 [cited 2017 Oct 30]. Available from: http://webbook.me.go.kr/DLiFile/NIER/09/022/5637095.pdf(Korean).

6. Barbosa F Jr, Tanus-Santos JE, Gerlach RF, Parsons PJ. A critical review of biomarkers used for monitoring human exposure to lead: advantages, limitations, and future needs. Environ Health Perspect 2005;113(12):1669-1674.

7. Fels LM, Wünsch M, Baranowski J, Norska-Borówka I, Price RG, Taylor SA, et al. Adverse effects of chronic low level lead exposure on kidney function--a risk group study in children. Nephrol Dial Transplant 1998;13(9):2248-2256.

8. Bellinger D, Sloman J, Leviton A, Rabinowitz M, Needleman HL, Waternaux C. Low-level lead exposure and children's cognitive function in the preschool years. Pediatrics 1991;87(2):219-227.

9. Centers for Disease Control and Prevention. Preventing lead poisoning in young children; 2005 [cited 2017 Oct 30]. Available from: https://www.cdc.gov/nceh/lead/publications/prevleadpoisoning.pdf.

10. Ha M. Environmental exposure and health survey in children and adolescents (IV). Incheon: National Institute of Environmental Research; 2014, p. 204-205 (Korean).

11. Wilhelm M, Heinzow B, Angerer J, Schulz C. Reassessment of critical lead effects by the German Human Biomonitoring Commission results in suspension of the human biomonitoring values (HBM I and HBM II) for lead in blood of children and adults. Int J Hyg Environ Health 2010;213(4):265-269.

12. Smith M. Recent work on low level lead exposure and its impact on behavior, intelligence, and learning: a review.J Am Acad Child Psychiatry 1985;24(1):24-32.

13. Glickman L, Valciukas JA, Lilis R, Weisman I. Occupational lead exposure. Effects on saccadic eye movements. Int Arch Occup Environ Health 1984;54(2):115-125.

14. Tong S, von Schirnding YE, Prapamontol T. Environmental lead exposure: a public health problem of global dimensions. Bull World Health Organ 2000;78(9):1068-1077.

15. Brunekreef $B$. The relationship between air lead and blood lead in children: a critical review. Sci Total Environ 1984;38:79-123.

16. Romieu I, Carreon T, Lopez L, Palazuelos E, Rios C, Manuel Y, et al. Environmental urban lead exposure and blood lead levels in children of Mexico City. Environ Health Perspect 1995;103(11): 1036-1040.

17. Bono R, Pignata C, Scursatone E, Rovere R, Natale P, Gilli G. Updating about reductions of air and blood lead concentrations in Turin, Italy, following reductions in the lead content of gasoline. Environ Res 1995;70(1):30-34.

18. He K, Wang S, Zhang J. Blood lead levels of children and its trend in China. Sci Total Environ 2009;407(13):3986-3993. 
19. Park JU, Oh SW, Kim SH, Kim YH, Park RJ, Moon JD. A study on the association between blood lead levels and habitual tobacco and alcohol use in Koreans with no occupational lead exposure. Korean J Occup Environ Med 2008;20(3):165-173 (Korean).

20. Jou HM, Cho TJ, Yang WH, Lee JW, Son BS. Lead levels in blood of residents in industrial area. J Environ Health Sci 2009;35(2):8694 (Korean).

21. National Institute of Environmental Research. Annual report of ambient air quality in Korea 2013. Incheon: National Institute of Environmental Research; 2014, p.18 (Korean).

22. Kang H. Statistical considerations in meta-analysis. Hanyang Med Rev 2015;35(1):23-32 (Korean).

23. Park KS. A study of lead concentrations in ambient air of major cities [dissertation]. Seoul: Hanyang University; 1993 (Korean).

24. Kim HJ, Hong YS, Lee KE, Kim DS, Lee MJ, Yeah BJ, et al. The levels of blood lead and cadmium in urban and rural population in Korea. J Life Sci 2009;19(4):472-478 (Korean).

25. Seo JH, Kim BG, Kim YM, Kim RB, Chung JY, Hong YS. Lead, mercury and cadmium concentration in blood and related factors among Korean preschoolers. J Environ Health Sci 2014;40(4):279293 (Korean).

26. US Environmental Protection Agency. America's children and the environment. 3rd ed. Washington, DC: US Environmental Protection Agency; 2013, p. 118-119.

27. Alarcon WA; State Adult Blood Lead Epidemiology and Surveillance (ABLES) Program Investigators. Elevated blood lead levels among employed adults-United States, 1994-2012. MMWR Morb Mortal Wkly Rep 2015;62(54):52-75.

28. Hwang YH, Ko Y, Chiang CD, Hsu SP, Lee YH, Yu CH, et al. Transition of cord blood lead level, 1985-2002, in the Taipei area and its determinants after the cease of leaded gasoline use. Environ Res 2004;96(3):274-282.

29. Lee DS, Lee YG, Hue JW, Lee SI, Son DH, Kim MG. Annual variation of atmospheric lead concentration in Seoul (1984-1993). J Korean Air Pollut Res Assoc 1994;10(3):170-174 (Korean).

30. Kim YA, Kim YN, Cho KD, Kim MY, Kim EJ, Baek OH, et al. Blood heavy metal concentrations of Korean adults by seafood consumption frequency: using the fourth Korea National Health and Nutrition Examination Survey (KNHANES IV), 2008. Korean J Nutr 2011;44(6):518-526 (Korean).

31. Hong YC. Scientific opinions on exposure recommendation level for susceptible population (II). Incheon: National Institute of Environmental Research; 2012, p. 16 (Korean). 